\title{
THINK GLOBALLY, ACT LOCALLY: EXPERT OPINIONS FROM ASIA ON THE DIAGNOSIS AND TREATMENT OF PEMPHIGUS VULGARIS
}

\author{
ZEYNAB SAMADI, FARZAM GOROUHI, PARASTOO DAVARI, ALIREZA FIROOZ
}

\section{ABSTRACT}

BACKGROUND: Pemphigus vulgaris (PV) is the most common blistering disease in Iran and many other Asian countries with a relatively high incidence and involvement of both skin and mucous membranes in majority of the patients. AIMS: To assess the opinions of Asian experts on the diagnosis and management of PV. SETTINGS AND DESIGN: It was a questionnaire-based mailed/e-mailed survey. MATERIALS AND METHODS: The questionnaire was sent to 29 dermatologists from different countries of Asia who treat autoimmune blistering disorders, with at least 5 years' experience in this field, and who visit at least five new PV patients annually. Questions included duration of experience, number of patients treated and diagnostic and treatment approaches for PV. STATISTICAL ANALYSIS USED: Percentage prevalence; some data are reported as mean \pm SD. RESULTS: All of the 29 physicians participated in the survey; among them, 79.3\% visit their patients within 6 months after the onset of symptoms. Diagnosis of PV is confirmed by histologic and direct immunofluorescence examinations by $65.5 \%$ of physicians. All of them initiate the treatment with corticosteroids $(48.3 \%$ with a dose of at least $2 \mathrm{mg} / \mathrm{kg} / \mathrm{day}$ prednisolone), and $89.7 \%$ add adjuvant immunosuppressors at the same time. Of the adjuvant agents used, azathioprine is used by $82.8 \%$ of physicians. CONCLUSIONS: Different trends in diagnostic techniques and treatment options for PV among the experienced authorities emphasize the urgent need for large-scale controlled trials in order to reach consensus standards in this field. In addition, regional and worldwide consensus meetings to consider all regional and genetic similarities and differences are highly recommended.

Key words: Corticosteroids, diagnosis, immunosuppressors, pemphigus, therapy

Pemphigus is an autoimmune blistering disorder that affects skin and mucous membranes. Pemphigus vulgaris (PV) is the most common form, which may be fatal if

Center for Research and Training in Skin Diseases and Leprosy, Tehran University of Medical

Sciences, Tehran, Iran

\section{Correspondence:}

Alireza Firooz, Center for Research and Training in Skin Diseases and Leprosy, Tehran University of Medical Sciences, 79 Taleghani Avenue, Tehran - 14166, Iran. E-mail: firozali@sina.tums.ac.ir left untreated.

PV has a prevalence rate of 30 per 100,000 population ${ }^{[1]}$ and an incidence rate of 1.0 per 100,000 /year (0.67-1.6) in Iran, ${ }^{[1-4]}$ which is much higher than many other countriesincidences varying from 0.076 in Finland ${ }^{[5]}$ to 0.67 in Tunesia. ${ }^{[6]}$ Only a population from Jerusalem $^{[7]}$ had an incidence of 1.6 per 100,000/year. 
The mean age at onset of disease was between 38 and 42 years (pooled data from various studies: $41.35 \pm 18.13$ years),,$^{[1-4]}$ which is similar to reports from other Middle East countries ${ }^{[7-9]}$ and less than reports from Europe and U.S.A. ${ }^{[10-14]}$

The majority $(70.4 \%)^{[1]}$ of Iranian PV patients had both mucosal and skin involvement, with poorer prognosis and more treatment resistance. ${ }^{[1-4]}$

According to a study on MHC markers, ${ }^{[15]}$ there is a possible common central Asian ancestral origin for non-Jewish Persian and Ashkenazi Jewish PV patients.

A wide variety of diagnostic and therapeutic approaches to PV, based on clinicians' experiences rather than solid evidence, exist. In this study, a survey was carried out to reveal the opinion of Asian expert dermatologists on diagnostic methods and management of PV.

\section{MATERIALS AND METHODS}

The study enrolled 29 dermatologists from different countries of Asia (23 from Iran and 6 from India, Kuwait, Turkey and Bangladesh) who are in charge of the treatment of autoimmune blistering disorders, with at least 5 years' experience in this field, and who visit at least five new PV patients annually. There was no discrimination and all potential candidates in Iran were invited and included. In addition, all potential Asian PV experts who had published at least one related paper with an available contact address were invited.
A questionnaire was mailed or e-mailed to study participants to assess their opinions about diagnostic and therapeutic approaches to PV. Information included duration of experience, number of patients treated annually and totally, number of new cases referred each year, diagnostic methods and treatment regimens.

The present study was approved by the Institutional Review Board of Center for Research and Training in Skin Diseases and Leprosy (CRTSDL), Tehran University of Medical Sciences.

\section{Statistical analysis}

SPSS version 11.5 for Windows software (SPSS Inc., Chicago, IL) was used to analyze the data. Some data are reported as mean \pm SD.

\section{RESULTS}

Table 1 shows the answers given about different aspects of PV diagnostic approaches based on country (Iranian vs. non-Iranian) and compares these with a previous study. ${ }^{[16]}$ In addition, Table 2 demonstrates the attitudes of surveyed experts towards the management of PV and compares these with a previous published study of Minouni et al. ${ }^{[16]}$

\section{Participants' characteristics}

Twenty-nine dermatologists responded and completed the questionnaires. They had a mean duration of experience of $17.4 \pm 4.9$ (range: 10 to 30 ) years in treating PV. Two physicians $(6.9 \%)$ had treated less than 100

Table 1: Diagnostic considerations as reported by Asian pemphigus vulgaris experts and their comparison with a similar previous report, mainly from USA and Europe

\begin{tabular}{|c|c|c|c|c|c|}
\hline & & $\operatorname{Iran}(n=23)$ & $\begin{array}{c}\text { Other Asian } \\
\text { countries }(n=6)\end{array}$ & $\begin{array}{l}\text { Total Asian } \\
\text { countries }(n=29)\end{array}$ & $\begin{array}{l}\text { USA and } \\
\text { Europe } 15(n=24)\end{array}$ \\
\hline Duration of PV therapy, mean years & & 17.2 & 18.9 & 17.5 & \multirow{5}{*}{$\begin{array}{c}20 \\
\text { Total of } 2050 \\
\text { patients }\end{array}$} \\
\hline \multirow[t]{4}{*}{ Total treated PV patients (\%) } & $<100$ & 4.3 & 16.7 & 6.9 & \\
\hline & $100-399$ & 56.5 & 66.7 & 58.6 & \\
\hline & $400-1000$ & 34.9 & 16.7 & 31.0 & \\
\hline & $>1000$ & 4.3 & 0.0 & 3.4 & \\
\hline \multirow{6}{*}{$\begin{array}{l}\text { No. of new PV patients treated } \\
\text { last year }(\%)\end{array}$} & & & & & \multirow{6}{*}{$\begin{array}{c}\text { Total of } 496 \\
\text { patients per year }\end{array}$} \\
\hline & $5-10$ & 34.9 & 33.3 & 34.5 & \\
\hline & $11-30$ & 26.1 & 66.7 & 34.5 & \\
\hline & $31-50$ & 13.0 & 0.0 & 10.3 & \\
\hline & $51-100$ & 21.7 & 0.0 & 17.2 & \\
\hline & $>100$ & 4.3 & 0.0 & 3.4 & \\
\hline \multirow[t]{4}{*}{ Referral delay (\%) } & $\begin{array}{l}3 \text { months or } \\
\text { less }\end{array}$ & 17.4 & 50.0 & 24.1 & 50.0 \\
\hline & 3 to 6 months & 60.9 & 33.3 & $55.2 S$ & \\
\hline & 6 to 12 months & 21.7 & & 17.2 & 16.7 \\
\hline & More than a year & 0.0 & 16.7 & 3.4 & 25.0 \\
\hline \multirow[t]{4}{*}{ Gold standard of PV diagnosis (\%) } & Histology & 13.0 & 16.7 & 13.8 & \\
\hline & Histology + DIF & 65.3 & & 65.5 & 95.8 \\
\hline & Histology + DIF + IIF & 21.7 & 16.7 & 20.7 & 0.0 \\
\hline & IIF & 0.0 & 0.0 & 0.0 & 4.2 \\
\hline
\end{tabular}

"Most data were reported as percentage due to uniformity of reporting, as in the study by Mimouni et al.[15]

PV - Pemphigus vulgaris, DIF - Direct immunofluorescence, IIF - Indirect immunofluorescence

patients, 17 (58.6\%) had treated 100-399, 9 (31.0\%) had treated $400-1,000$ and 1 (3.4\%) had treated more than 1,000 patients with PV during their lifetime. Ten dermatologists (34.5\%) treat 5-10 new cases of PV each year, $10(34.5 \%)$ treat $10-29,3(10.3 \%)$ treat $30-49,5(17.2 \%)$ treat $50-99$ and $1(3.4 \%)$ treats 100 or more new patients yearly.

\section{Referral delay}

Twenty-three (79.3\%) clinicians reported that they see the patients within 6 months after the onset of symptoms; 5 (17.2\%) physicians reported that they receive referrals between 6 months and 1 year; while 1 (3.4\%) reported a lag time of more than 1 year from symptom onset to referral.

\section{Diagnosis}

Nineteen $(65.5 \%)$ of the study participants establish the diagnosis of PV by histologic and direct immunofluorescence (DIF) studies; $6(20.7 \%)$ consider histology, DIF and indirect immunofluorescence (IIF) to confirm their diagnosis. Four $(13.8 \%)$ clinicians make diagnosis only on histologic evidence.

\section{Therapy}

\section{Treatment protocol}

All of the clinicians use corticosteroids initially in treatment of PV. Twenty-six $(89.7 \%)$ clinicians initiate the therapy in conjunction with an adjuvant immunosuppressant, and two (8.7\%) initiate with prednisolone alone. Among those who administer corticosteroids in combination with an adjuvant, three Indian experts (10.3\%) prefer to prescribe dexamethasonecyclophosphamide pulse, ${ }^{[17,18]}$ and all others use prednisolone plus immunosuppressant. 
Table 2: Therapeutic considerations as reported by Asian pemphigus vulgaris experts and their comparison with a similar previous report, mainly from USA and Europe

\begin{tabular}{|c|c|c|c|c|c|}
\hline & & $\operatorname{Iran}(n=23)$ & $\begin{array}{l}\text { Other Asian } \\
\text { countries }(n=6)\end{array}$ & $\begin{array}{c}\text { Total Asian } \\
\text { countries }(n=29)\end{array}$ & $\begin{array}{l}\text { USA and Europe } \\
15(n=24)^{*}\end{array}$ \\
\hline \multirow[t]{4}{*}{ Initial treatment protocol (\%) } & $\begin{array}{l}\text { Prednisolone alone } \\
\text { Prednisolone + steroid- }\end{array}$ & 8.7 & 16.7 & 10.3 & 45.8 \\
\hline & $\begin{array}{l}\text { sparing agent } \\
\text { Dapsone or gold or }\end{array}$ & 91.3 & 50.0 & 82.8 & 16.7 \\
\hline & $\begin{array}{l}\text { tetracycline } \\
\text { Dexamethasone- } \\
\text { cyclophosphamide }\end{array}$ & 0.0 & 16.7 & 3.4 & 20.1 \\
\hline & pulse & 0.0 & 33.3 & 6.9 & 0.0 \\
\hline & $1 \mathrm{mg} / \mathrm{kg} / \mathrm{d}$ & 8.7 & 16.7 & 10.3 & 50.0 \\
\hline \multirow{3}{*}{ prednisolone (\%) } & $1-1.5 \mathrm{mg} / \mathrm{kg} / \mathrm{d}$ & 13.0 & 33.3 & 17.2 & 31.0 \\
\hline & $1.5-2 \mathrm{mg} / \mathrm{kg} / \mathrm{d}$ & 21.7 & 33.3 & 24.1 & 19.0 \\
\hline & $\geq 2 \mathrm{mg} / \mathrm{kg} / \mathrm{d}$ & 56.5 & 16.7 & & \\
\hline \multirow{4}{*}{$\begin{array}{l}\text { Final dosage of prednisolone } \\
\text { in a controlled patient (\%) }\end{array}$} & & & & & \\
\hline & $\begin{array}{c}0 \mathrm{mg} / \mathrm{d} \\
5 \mathrm{mg} \text { alternate daily }\end{array}$ & $\begin{array}{c}69.6 \\
4.3\end{array}$ & $\begin{array}{c}66.7 \\
0.0\end{array}$ & $\begin{array}{c}69.0 \\
3.4\end{array}$ & $\begin{array}{l}37.0 \\
11.0\end{array}$ \\
\hline & $5 \mathrm{mg} / \mathrm{d}$ & 26.1 & 16.7 & 24.1 & 26.0 \\
\hline & $10 \mathrm{mg} / \mathrm{d}$ & 0.0 & 16.7 & 3.4 & 26.0 \\
\hline \multirow{5}{*}{$\begin{array}{l}\text { Choice of adjuvant } \\
\text { therapy (\%) azathioprine }\end{array}$} & & & & & \\
\hline & $\begin{array}{l}91.3 \\
\text { Mycophenolate mofetil }\end{array}$ & $\begin{array}{c}50.0 \\
0.0\end{array}$ & 0.0 & $\begin{array}{c}44.0 \\
0.0\end{array}$ & \\
\hline & Cyclophosphamide & 4.3 & 50.0 & 13.8 & 16.0 \\
\hline & $\begin{array}{l}\text { Cyclosporine } \\
\text { Mycophenolate mofetil }\end{array}$ & & 0.0 & 3.4 & 4.0 \\
\hline & and methotrexate & & & 0.0 & 8.0 \\
\hline \multirow{2}{*}{$\begin{array}{l}\text { Maintenance duration for } \\
\text { adjuvant agent (\%) }\end{array}$} & 6 to 12 months & & & 37.9 & 46.0 \\
\hline & $\begin{array}{l}1 \text { to } 2 \text { years } \\
>2 \text { vears }\end{array}$ & & $\begin{array}{l}50.0 \\
16.7\end{array}$ & $\begin{array}{c}55.2 \\
6.9\end{array}$ & 36.0 \\
\hline \multirow{6}{*}{$\begin{array}{l}\text { Disease control } \\
\text { definition (\%) }\end{array}$} & & & & & \\
\hline & Absence of new blisters & 82.7 & 50.0 & 75.9 & 53.0 \\
\hline & $\begin{array}{l}\text { Blister free skin } \\
\text { Healing of most lesions }\end{array}$ & & 50.0 & 10.3 & 15.0 \\
\hline & $\begin{array}{l}\text { and negative Nikolsky sig } \\
\text { Healing of most lesions an }\end{array}$ & & 0.0 & 3.4 & 0.0 \\
\hline & negative Nikolsky sign & 13.0 & 0.0 & 10.3 & 0.0 \\
\hline & of blisters & 0.0 & 0.0 & 0.0 & 32.0 \\
\hline
\end{tabular}

${ }^{*}$ Most data were reported as percentage due to uniformity of reporting, as in the study by Mimouni et al.[15]

None of the participating experts currently uses other nonsteroidal agents (gold, tetracycline, dapsone) as the first choice in therapeutic regimen except one dermatologist, who sometimes considers dapsone as an initial therapy.

\section{Initial prednisolone dosage}

Three of them (10.3\%) prescribe prednisolone at a dose of $1 \mathrm{mg} / \mathrm{kg} / \mathrm{day}, 5$ (17.2\%) administer 1-1.5 mg/kg/day, 7 (24.1\%) administer 1.5 up to $2 \mathrm{mg} / \mathrm{kg} /$ day and 13 (56.5\%) administer at least $2 \mathrm{mg} / \mathrm{kg} / \mathrm{day}$ at the time of diagnosis.

\section{Preferred corticosteroids sparing immunosuppressors}

Of all the adjuvant immunosuppressive agents, azathioprine is used by $24(82.8 \%)$ of the physicians; cyclophosphamide is used by $4(13.8 \%)$ and cyclosporine is prescribed by only $1(3.4 \%)$ physician.

\section{Tapering method}

Considering the long-term strategy, 20 (69.0\%) physicians reported that they set their goal to discontinue corticosteroid therapy completely, whereas 1 (3.4\%) stated an alternate daily prednisolone dose of $5 \mathrm{mg}$ as the ultimate goal and $7(24.1 \%)$ had a goal of prescribing prednisolone at a dose of $5 \mathrm{mg}$ daily. Eleven dermatologists (37.2\%) keep on using the immunosuppressor for 6 months to 1 year, $16(55.2 \%)$ maintain the regimen for 1 to 2 years and $2(6.9 \%)$ continue immunosuppressive therapy for more than 2 years.

\section{Disease control definition}

Of the clinicians questioned, 22 (75.9\%) defined disease control as the development of no new lesions and healing of most of the previous lesions; 1 (3.4\%) defined it as vanishing of most of the lesions with negative Nikolsky's sign; 3 (10.3\%) considered the control of disease as healing of majority of lesions, appearance of no new lesions, with negative Nikolsky's sign; and 3 $(10.3 \%)$ define disease control as blister-free skin.

\section{Corticosteroids vs. immunosuppressors}

Following control of PV, 21 Iranian dermatologists $(91.3 \%)$ stated that they reduce the immunosuppressor dose after the reduction in corticosteroid dose, whereas 2 Iranian (8.7\%) clinicians reported that they initially decrease the dose of immunosuppressor.

\section{DISCUSSION}

Since the worthwhile advent corticosteroids in 1950s, the fatal outcome and grave prognosis of $\mathrm{PV}$ have altered dramatically, albeit corticosteroid-induced morbidities.

In this study, the opinion of Asian (mostly west Asia) dermatologists with great experience in PV was obtained.

The differences between the present study and the study by Mimouni et al..[16] in term of more rapid referral of $\mathrm{PV}$ patients to expert dermatologists could be rationalized by differences in disease severity at onset.

Clinical features of skin and mucosal lesions, demonstration of acanothlysis in biopsy specimens and demonstration of pemphigus autoantibodies in tissue, serum or both are the three main clues to confirmation of PV diagnosis. ${ }^{[19]}$ In this study, it was found that about two-thirds of the physicians confirm their diagnosis by histologic and DIF examinations.

Considering the role of pemphigus autoantibodies in the pathogenesis of PV, it seems that a step-by-step treatment with moderate doses of corticosteroids in combination with immunosuppressors - to maximize efficacy and minimize the corticosteroid-related morbidities - is a safe and effective therapeutic approach. ${ }^{[16]} \mathrm{We}$ observed that all of the experts initiate the treatment of $\mathrm{PV}$ with corticosteroids, either alone or in conjunction with immunosuppressors. However, the study by Mimouni et al. revealed that $25 \%$ of physicians initially use nonsteroidal agents (gold, tetracycline, dapsone) or try to 
eliminate potential triggers. ${ }^{[16]}$ In the present study, only one expert prefers dapsone as an optional initial therapy in some circumstances.

Another important finding is that the majority of experts (82.8\%) add adjuvant immunosuppressor to corticosteroid at the time of treatment initiation, contrary to $16.7 \%$ reported by Mimouni et al. ${ }^{[16]}$ This fact can be simply explained by the severe nature of the disease in Asia.

Most of the participating physicians initiate prednisolone at a dose of more than $1.5 \mathrm{mg} /$ $\mathrm{kg} /$ day $(72.4 \%)$, whereas half of US/European dermatologists ${ }^{[16]}$ initiate prednisolone therapy with $1 \mathrm{mg} / \mathrm{kg} /$ day. In one 20-year study, 782 out of 1,111 Iranian PV patients (70.4\%) had both skin and mucous membrane involvement. ${ }^{[1]}$ Hence, so many dermatologists in Iran and some other Asian countries prefer to start with higher doses of prednisolone, mostly in combination with an adjuvant drug from the beginning. The dosage is often reduced by $30 \%$ after clinical response in 10-14 days and then tapered by $10 \mathrm{mg} /$ week until $30 \mathrm{mg}$ and slower afterwards. ${ }^{[20]}$ Even many experts who preferred treating $P V$ with $1 \mathrm{mg} / \mathrm{kg}$ prednisolone increase the dosage in a stepwise manner in case of a lack of response after 5-7 days. ${ }^{[21,22]}$

Similar to other countries, ${ }^{[16]}$ azathioprine is the most frequently prescribed immunosuppressive agent by Asians. This may be due to its lower cost, proven efficacy and acceptable safety profile even in combination with high doses of prednisolone. ${ }^{[23,24]}$ Nausea and increased blood pressure are the most common adverse events for $2 \mathrm{mg} / \mathrm{kg}$ azathioprine plus $2 \mathrm{mg} / \mathrm{kg}$ prednisolone seen in a trial. ${ }^{[24]}$ None of the Asian experts prefer to use Mycophenolate mofetil as an adjuvant primarily, which is contrary to US/European study. ${ }^{[16]}$

Moreover, we found that most of the experts $(69.0 \%)$ consider the complete discontinuation of corticosteroids as their final goal of treatment. Paradoxically, only $37 \%$ of US/European experts ${ }^{[16]}$ eliminate prednisolone after disease control.

(c)

A considerable proportion of physicians $(75.9 \%)$ in this study defined disease control as the development of no new lesions and healing of most of the previous lesions, confirming previous findings with less controversial choices among Asians.

No

The main limitation of this study could be that we cannot completely generalize the attitudes of the whole continent. However, the study promotes so many controversies in expert opinions from different parts of the world (old world vs. new world), which can be explained in different fashions.

To sum up, a wide variety of diagnostic and therapeutic approaches to PV is apparent among the most experienced clinicians in this field. Therefore, large-scale randomized controlled trials would be essential to resolve existing controversies in the management of such potentially fatal disease and to achieve a consensus among authorities on the matter.

In addition, as PV is widely variable in different parts of the world and in the absence of any published systematic reviews, regional and worldwide consensus meetings to implement all similarities and differences with respect to genetic background, degree of disease resistance and cultural concerns in different regions are highly recommended.

\section{ACKNOWLEDGMENT}

We would like to thank all PV experts who participated in this study or helped us in this regard. A. Firooz has full access to all the data in this study and takes responsibility for the integrity of the data and the accuracy of the data analysis.

\section{REFERENCES}

1. Chams-Davatchi $C$, Valikhani M, Daneshpazhooh M, Esmaili N, Balighi K, Hallaji Z, et al. Pemphigus Analysis of 1209 cases. Int $\int$ Dermatol 2005;44:470-6.

2. Salmanpour R, Shahkar H, Namazi MR, RahmanShenas MR. Epidemiology of pemphigus in southwestern Iran: A 10-year retrospective study (19912000). Int J Dermatol 2006:45:103-5.

3. Shamsadini S, Fekri AR, Esfandiarpoor I, Saryazdi S, Rahnama Z, Zandi S, et al. Determination of survival and hazard functions for pemphigus patients in Kerman, a southern province of Iran. Int J Dermatol 2006;45:668-71.

4. Asilian A, Yoosefi A, Faghini G. Pemphigus vulgaris in Iran: Epidemiology and clinical profile. Skinmed 2006;5:69-71.

5. Hietanen J, Salo OP. Pemphigus: An epidemiological study of patients treated in Finnish hospitals between 1969 and 1978. Acta Derm Venereol 1982;62:491-6.
6. Haouet H, Ben Hamida A, Haouet S, Chaffai M Ben Osman A. Tunisian pemphigus. Apropos of 70 cases. (Experience of the dermatology department of La Rabta Hospital 1974-92). Ann Dermatol Venereol 1996;123:9-11.

7. Nanda A, Dvorak R, Al-Saeed K, Al-Sabah H, Alsaleh QA. Spectrum of autoimmune bullous diseases in Kuwait. Int J Dermatol 2004;43:876-81.

8. Hafeez ZH. Pemphigus in Pakistan, A study of 108 cases. J Pak Med Assoc 1998;48:9-10.

9. Uzun S, Durdu M, Akman A, Gunasti S, Uslular C Memisoglu HR, et al. Pemphigus in the Mediterranean region of Turkey: A study of 148 cases. Int J Dermatol 2006;45:523-8.

10. Pisanti S, Sharav $Y$, Kaufman E, Posner LN Pemphigus vulgaris: Incidence in Jews of differen ethnic groups, according to age, sex and initia lesion. Oral Surg Oral Med Oral Patho 1974;38:382-7.

11. Naldi $L$, Bertoni $M$, Cainelli $T$. Feasibility of a registry of pemphigus in Italy: Two years experience. Gruppo Italiano Studi Epidemiologici in Dermatologia (GISED). Int J Dermato 1993;32:424-7.

12. Bastuji-Garin S, Souissi R, Blum L, Turki H, Nouira $\mathrm{R}$, Jomaa $\mathrm{B}$, et al. Comparative epidemiology of pemphigus in Tunisia and France. Incidence of foliaceus pemphigus in young Tunisian women. Ann Dermatol Venereol 1996;123:337-42.

13. Wilson C, Wojnarowska F, Mehra NK, Pasricha JS. Pemphigus in Oxford, UK and New Delhi, India: A comparative study of disease characteristics and HLA antigens. Dermatology 1994;189:108-10.

14. Alhashimi M, Pittelkow M. Epidemiology of pemphigus in Olmsted County, Minnesota from 1950-2000. J Am Acad Dermatol 2005;53:104.

15. Mobini N, Yunis EJ, Alper CA, Yunis JJ, Delgado JC, Yunis DE, et al. Identical MHC markers in nonJewish Iranian and Ashkenazi Jewish patients with pemphigus vulgaris: Possible common central Asian ancestral origin. Hum Immunol 1997;57:62-7.

16. Mimouni D, Nousari CH, Cummins DL, Kouba DJ, David M, Anhalt GJ. Differences and similarities 
among expert opinions on the diagnosis and treatment of pemphigus vulgaris. J Am Acad Dermatol 2003;49:1059-62.

17. Pasricha JS, Khaitan BK, Raman RS, Chandra M. Dexamethasone-cyclophosphamide pulse therapy for pemphigus. Int J Dermatol 1995;34:875-82.

18. Kanwar AJ, Kaur S, Thami GP. Long-term efficacy of dexamethasone-cyclophosphamide pulse therapy in pemphigus. Dermatology 2002;204:22831.

19. Bystryn JC, Rudolph JL. Pemphigus. Lancet 2005;366:61-73.

20. Chams-Davatchi C, Daneshpazhooh M. Prednisolone dosage in pemphigus vulgaris. J Am Acad Dermatol 2005;53:547.

21. Enk AH, Knop J. Mycophenolate mofetil is effective in the treatment of pemphigus vulgaris. Arch
Dermatol 1999;135:54-6.

22. Fleischli ME, Valek RH, Pandya AG. Pulse intravenous cyclophosphamide therapy in pemphigus. Arch Dermatol 1999;135:57-61.

23. Mentink LF, Mackenzie MW, Toth GG, Laseur M, Lambert FP, Veeger NJ, et al. Randomized controlled trial of adjuvant oral dexamethasone pulse therapy in pemphigus vulgaris: PEMPULS trial. Arch Dermatol 2006;142:570-6.

24. Beissert S, Werfel T, Frieling U, Bohm M, Sticherling $\mathrm{M}$, Stadler R, et al. A comparison of oral methylprednisolone plus azathioprine or mycophenolate mofetil for the treatment of pemphigus. Arch Dermatol 2006;142:1447-54.

Source of Support: Nil, Conflict of Interest: None declared.

\section{Announcement}

\section{JPGM WriteCon 2007 \\ A Conference on Medical Writing \\ 30-31 ${ }^{\text {st }}$ March, 2007 \\ Mumbai, India}

Venue: Seth GS Medical College and KEM Hospital, Mumbai - 400012

TOPICS

IMARD: The age old structure for scientific papers

Attracting readers: The importance of title and abstract

Tables and Figures: Making figures worth 1000 words

The 'structured discussion': The evidence based discussion

Standardized reporting guidelines: The helping hands

Reporting statistics: The common errors editors won't miss to pickup

The peer review process: Easier to pass through when you know how it works

'I wish I had written that paper': The publishable paper

Authors vs. contributors: The importance of names in byline

Ethical conduct of research: When and how of IRBs

and more...

For details: E-mail: www.jpgmonline.com/writecon.asp 